\title{
Case-control study on factors associated with a decreased milk yield and a depressed health status of dairy herds in northern Germany
}

Katharina Charlotte Jensen ${ }^{1,2^{*}}$ (D), Cornelia Frömke ${ }^{2,3}$, Bettina Schneider ${ }^{1}$, Phuong Do Duc ${ }^{2}$, Frieder Gundling ${ }^{2}$, Katrin Birnstiel ${ }^{2}$, Franziska Schönherr², Theresa Scheu ${ }^{2,4}$, Anika Kaiser-Wichern ${ }^{2,5}$, Svenja Woudstra ${ }^{6,2}$,

Christian Seyboldt', Martina Hoedemaker ${ }^{2}$ and Amely Campe ${ }^{1}$

\begin{abstract}
Background: In the past years, it became apparent that health status and performance differ considerably within dairy farms in Northern Germany. In order to obtain clues with respect to possible causes of these differences, a case-control study was performed. Case farms, which showed signs of health and performance problems, and control farms, which had none of these signs, were compared. Risk factors from different areas such as health management, housing, hygiene and nutrition were investigated as these are known to be highly influential. The aim of this study was to identify major factors within these areas that have the strongest association with health and performance problems of dairy herds in Northern Germany.
\end{abstract}

Results: In the final model, a lower energy density in the roughage fraction of the diet, more pens with dirty lying areas and a low ratio of cows per watering spaces were associated with a higher risk for herd health problems. Moreover, case farms were affected by infections with intestinal parasites, lungworms, liver flukes and Johne's Disease numerically more often than control farms. Case farms more often had pens with raised cubicles compared to the deep bedded stalls or straw yards found in control farms. In general, the hygiene of the floors and beddings was worse in case farms. Concerning nutrition, the microbiological and sensory quality of the provided silages was often insufficient, even in control farms. Less roughage was provided to early lactating cows and the feed was pushed to the feeding fence less frequently in case farms than in control farms.

Conclusions: The results show that milk yield and health status were associated with various factors from different areas stressing the importance of all aspects of management for good animal health and performance. Moreover, this study confirmed well-known risk factors for health problems and performance losses. These should better be taken heed of in herd health management.

Keywords: Dairy cow, Health management, Housing, Hygiene, Feeding management

\footnotetext{
* Correspondence: Charlotte.Jensen@tiho-hannover.de

'Department of Biometry, Epidemiology and Information Processing, WHO Collaborating Center for Research and Training for Health at the

Human-Animal-Environment Interface, and Clinic for Cattle, University of

Veterinary Medicine Hannover, Foundation, Hannover, Germany

${ }^{2}$ Clinic for Cattle, University of Veterinary Medicine, Foundation, Hannover,

Germany

Full list of author information is available at the end of the article
}

(C) The Author(s). 2019 Open Access This article is distributed under the terms of the Creative Commons Attribution 4.0 International License (http://creativecommons.org/licenses/by/4.0/), which permits unrestricted use, distribution, and

reproduction in any medium, provided you give appropriate credit to the original author(s) and the source, provide a link to the Creative Commons license, and indicate if changes were made. The Creative Commons Public Domain Dedication waiver (http://creativecommons.org/publicdomain/zero/1.0/) applies to the data made available in this article, unless otherwise stated. 


\section{Background}

With an amount of approximately $32,600,000 \mathrm{t}$ milk produced in 2016, Germany produced more milk than any other country in the European Union. For Germany, dairy industry is the most important sector of agricultural industry. Dairy farming experienced a substantial structural change in Germany in the last decades. From 2010 to 2016, the number of farms dropped by approximately $23 \%$, while the number of cows stayed nearly the same [1]. This rapid change confronted the farmers with new tasks, such as human resources management. The mean milk yield per cow and year rose from $6208 \mathrm{~kg}$ in 2000 to $8059 \mathrm{~kg}$ in 2016 [2]. The higher milk yield challenges the farmers with higher demands concerning housing and feeding.

Since the 1990ies, it was reported that health and performance problems above-average occurred in a substantial number of dairy farms in (Northern) Germany $[3,4]$. First, some farmers and veterinarians assumed infectious agents to cause these problems. In particular, Clostridium botulinum (C. botulinum) was supposed to be the main cause of these problems and a new form of toxicoinfection named chronic or visceral botulism was postulated [3]. This issue has initiated a very controversial debate among the veterinary and dairy community in Germany [5]. For this reason, an extensive casecontrol study was conducted to detect an association between poor health status and C. botulinum and its toxin, respectively. However, no association could be substantiated $[6,7]$. Under the light of the undoubtable existence of severe health problems in dairy herds, the question of possible other causes was still unanswered. As no pathognomonic clinical picture could be observed, but many different symptoms [3], various causes had to be considered. Therefore, a systematic examination of herd health management was necessary.

For this reason, within the case-control study on $C$. botulinum, also different areas of dairy management were analyzed to identify possible causes for problems with health and milk yield in an explorative approach. Well known risk factors from the areas health management, housing, hygiene and nutrition were considered as they may have a substantial effect on milk yield and health status of dairy herds. These risk factors interact in a complex system and can influence several outcomes. To explore the current situation of this complex system, it was examined how risk factors from different areas of farm management were associated with a general, composed endpoint indicating health and performance problems. The hypothesis was to identify associations between risk factors from the areas health management, housing, hygiene and nutrition and a decreased milk yield, an increased mortality, an increased culling rate, an increased number of downer cows and farmers' or veterinarians' impression of herd health problems of dairy herds in Northern Germany.

\section{Results \\ Participants}

In the statistical analyses, 92 farms were included, of which 45 farms were case farms and 47 farms were control farms. Case farms were defined to fulfil at least 3 of the following five criteria: reduced milk yield ( $>15 \%$ for at least three months compared to the milk yield of the year before), increased mortality ( $>5 \%$ of the herd during the last year), increased culling rate ( $>35 \%$ of the herd during the last year or an increase of $>10 \%$ compared to the year before), increased number of downer cows ( $>10 \%$ of the herd during the last year) and farmers' or veterinarians' impression of herd health problems. Control farms fulfilled none of these criteria. Most farms kept mainly Holstein Friesians, but 11 farms (8 control and 3 case farms) kept Red Holsteins or crossbreeds. Milk yield was lower on case farms (case farms: $22.8 \mathrm{~kg}$ per cow and day, control farms: $26.0 \mathrm{~kg}$ per cow and day), due to the first inclusion criterion, the decreased milk yield.

\section{Risk factors}

The results of descriptive analyses and single-factorial logistic regression analyses are shown in Tables 1 and 2 . The results of the final multifactorial analysis are shown in Table 3. Factors from three of four areas of farm management (housing, hygiene and nutrition) revealed a statistically significant relationship with the current health and performance status in the investigated farms in multifactorial modeling.

\section{Health management}

Herds of case farms were numerically more often infected with liver flukes, lungworms, Mycobacterium avium ssp. paratuberculosis (MAP) and intestinal parasites than herds of control farms (Table 1). In the multifactorial model, these risk factors were not statistically significant.

Lameness was a serious problem in case farms [8]. Nevertheless, no relevant differences between case- and control farms were detected concerning the claw trimming interval, claw condition, and presence of dermatitis digitalis.

\section{Housing}

Regardless of the status group, more than $50 \%$ of farms had more cows than cubicles in pens. Pronounced overcrowding concerning the feeding spaces ( $>1.5$ ) occurred numerically more often in control than in case farms. Case farms had less often a ratio of 1 to 1.5 and more often had a good $(<1)$ or worse $(>1.5)$ ratio. This finding was significant in the multifactorial model. 
Table 1 Descriptive and single-factorial analyses of risk factors for health and performance problems in dairy farms in Northern Germany (qualitative variables); a varying number of farms is due to missing values

\begin{tabular}{|c|c|c|c|c|c|c|c|c|c|}
\hline \multirow[t]{2}{*}{ Risk factors } & \multirow[t]{2}{*}{ Category } & \multicolumn{2}{|c|}{ Cases } & \multicolumn{2}{|c|}{ Controls } & \multicolumn{4}{|c|}{ Single factorial analyses } \\
\hline & & $\mathrm{N}$ & $\%$ & $\mathrm{~N}$ & $\%$ & $\mathrm{OR}$ & $\mathrm{LCL}$ & UCL & $P$ \\
\hline \multicolumn{10}{|l|}{ Health Management } \\
\hline \multicolumn{10}{|l|}{ Infectious diseases } \\
\hline \multirow[t]{2}{*}{ Positive for liver flukes } & $\mathrm{No}^{1}$ & 31 & 68.9 & 38 & 80.9 & 1 & & & \\
\hline & Yes & 14 & 31.1 & 9 & 19.2 & 1.91 & 0.73 & 4.99 & 0.1887 \\
\hline \multirow[t]{2}{*}{ Positive for lungworms } & $\mathrm{No}^{1}$ & 28 & 62.2 & 37 & 78.7 & 1 & & & \\
\hline & Yes & 17 & 37.8 & 10 & 21.3 & 2.25 & 0.89 & 5.65 & 0.0855 \\
\hline \multirow[t]{2}{*}{ Positive for intestinal parasites } & $\mathrm{No}^{1}$ & 21 & 46.7 & 32 & 68.1 & 1 & & & \\
\hline & Yes & 24 & 53.3 & 15 & 31.9 & 2.44 & 1.04 & 5.69 & 0.0394 \\
\hline \multirow[t]{2}{*}{ Positive for MAP } & $\mathrm{No}^{1}$ & 40 & 88.9 & 45 & 95.7 & 1 & & & \\
\hline & Yes & 4 & 8.9 & 1 & 2.1 & 4.49 & 0.48 & 41.79 & 0.1873 \\
\hline \multicolumn{10}{|l|}{ Claw Health } \\
\hline \multirow[t]{2}{*}{ Claw with high-grade dermatitis digitalis } & $\mathrm{No}^{1}$ & 22 & 48.9 & 26 & 55.3 & 1 & & & \\
\hline & Yes & 23 & 51.1 & 21 & 44.7 & 1.29 & 0.57 & 2.94 & 0.5374 \\
\hline \multirow[t]{3}{*}{ Number out of ten examined cows with poor claw condition } & No $\operatorname{cow}^{1}$ & 27 & 60.0 & 29 & 61.7 & 1 & & & $0.1426^{2}$ \\
\hline & One cow & 7 & 15.6 & 13 & 27.7 & 0.58 & 0.20 & 1.67 & 0.3104 \\
\hline & $>$ one cow & 11 & 24.4 & 5 & 10.6 & 2.36 & 0.73 & 7.69 & 0.1533 \\
\hline \multirow[t]{3}{*}{ Frequency of herd claw trimming } & monthly or quarterly ${ }^{1}$ & 3 & 6.7 & 5 & 10.6 & 1 & & & $0.7800^{2}$ \\
\hline & Half-yearly & 23 & 51.1 & 22 & 46.8 & 1.74 & 0.37 & 8.18 & 0.4815 \\
\hline & $\begin{array}{l}\text { > half-yearly/ } \\
\text { irregularly }\end{array}$ & 19 & 42.2 & 20 & 42.6 & 1.58 & 0.33 & 7.56 & 0.5645 \\
\hline \multicolumn{10}{|l|}{ Housing } \\
\hline \multicolumn{10}{|l|}{ Stocking density } \\
\hline \multirow[t]{3}{*}{ Average ratio of cows per watering place } & $\leq 1^{1}$ & 15 & 33.3 & 9 & 19.2 & 1 & & & $0.1033^{2}$ \\
\hline & $1.01-1.5$ & 16 & 35.6 & 27 & 57.5 & 0.36 & 0.13 & 1.00 & 0.0498 \\
\hline & $>1.5$ & 14 & 31.1 & 11 & 23.4 & 0.77 & 0.24 & 2.40 & 0.6438 \\
\hline \multirow[t]{3}{*}{ Average ratio of cows per feeding place } & $\leq 1^{1}$ & 14 & 31.1 & 10 & 21.3 & 1 & & & $0.3551^{2}$ \\
\hline & $1.01-1.5$ & 25 & 55.6 & 26 & 55.3 & 0.69 & 0.26 & 1.83 & 0.4523 \\
\hline & $>1.5$ & 6 & 13.3 & 11 & 23.4 & 0.39 & 0.11 & 1.41 & 0.1501 \\
\hline \multirow[t]{2}{*}{ Average ratio of cows per cubicle } & $\leq 1^{1}$ & 21 & 46.7 & 21 & 44.7 & 1 & & & \\
\hline & $>1$ & 24 & 53.3 & 26 & 55.3 & 0.92 & 0.41 & 2.10 & 0.8484 \\
\hline \multicolumn{10}{|l|}{ Comfort of cubicles } \\
\hline \multirow[t]{3}{*}{$\%$ of pens with raised cubicles } & No pen ${ }^{1}$ & 9 & 20.0 & 15 & 31.9 & 1 & & & $0.0465^{2}$ \\
\hline & $1-99 \%$ of pens & 12 & 26.7 & 19 & 40.4 & 1.06 & 0.35 & 3.16 & 0.9270 \\
\hline & All pens & 24 & 53.3 & 13 & 27.7 & 3.08 & 1.06 & 8.94 & 0.0390 \\
\hline Number of pens with no bedding material in cubicles & No pen ${ }^{1}$ & 29 & 64.4 & 32 & 68.1 & 1 & & & \\
\hline & $\geq 1$ pen & 16 & 35.6 & 15 & 31.9 & 1.18 & 0.50 & 2.80 & 0.7120 \\
\hline Number of pens with no bedding material nor rubber mats in cubicles & No pen ${ }^{1}$ & 40 & 88.9 & 38 & 80.9 & 1 & & & \\
\hline & $\geq 1$ pen & 5 & 11.1 & 9 & 19.2 & 0.53 & 0.16 & 1.72 & 0.2885 \\
\hline Dimensions of cubicles & & & & & & & & & \\
\hline Average height of neck rail of cubicles $>115 \mathrm{~cm}$ & Yes $^{1}$ & 26 & 57.8 & 26 & 55.3 & 1 & & & \\
\hline & No & 19 & 42.2 & 21 & 44.7 & 0.91 & 0.40 & 2.07 & 0.8121 \\
\hline Average width of cubicles $>120 \mathrm{~cm}$ & Yes $^{1}$ & 0 & 0.0 & 0 & 0.0 & no lo & gistic & regress & sion \\
\hline & No & 47 & 100.0 & 47 & 100.0 & & & & \\
\hline
\end{tabular}


Table 1 Descriptive and single-factorial analyses of risk factors for health and performance problems in dairy farms in Northern Germany (qualitative variables); a varying number of farms is due to missing values (Continued)

\begin{tabular}{|c|c|c|c|c|c|c|c|c|c|}
\hline \multirow[t]{2}{*}{ Risk factors } & \multirow[t]{2}{*}{ Category } & \multicolumn{2}{|c|}{ Cases } & \multicolumn{2}{|c|}{ Controls } & \multicolumn{4}{|c|}{ Single factorial analyses } \\
\hline & & $\mathrm{N}$ & $\%$ & $\mathrm{~N}$ & $\%$ & $\mathrm{OR}$ & $\mathrm{LCL}$ & UCL & $P$ \\
\hline \multirow[t]{2}{*}{ Average distance from neck rail to curb $>195 \mathrm{~cm}$} & Yes $^{1}$ & 33 & 73.3 & 36 & 76.6 & 1 & & & \\
\hline & No & 12 & 26.7 & 11 & 23.4 & 1.19 & 0.46 & 3.06 & 0.7181 \\
\hline \multicolumn{10}{|l|}{ Floors } \\
\hline \multirow[t]{3}{*}{$\%$ of pens with slippery floors } & None $^{1}$ & 21 & 46.7 & 20 & 42.6 & 1 & & & $0.4259^{2}$ \\
\hline & $1-49 \%$ of pens & 5 & 11.1 & 10 & 21.3 & 0.48 & 0.14 & 1.64 & 0.2394 \\
\hline & $\geq 50 \%$ of pens & 19 & 42.2 & 17 & 36.2 & 1.06 & 0.43 & 2.61 & 0.8914 \\
\hline \multirow[t]{2}{*}{ Number of pens with damaged floors } & No pen ${ }^{1}$ & 36 & 80.0 & 42 & 89.4 & 1 & & & \\
\hline & $\geq 1$ pen & 9 & 20.0 & 5 & 10.6 & 2.10 & 0.65 & 6.84 & 0.2180 \\
\hline \multicolumn{10}{|l|}{ Hygiene } \\
\hline \multirow[t]{3}{*}{$\%$ of pens with dirty or very dirty floors } & $0-49 \%$ of pens ${ }^{1}$ & 5 & 11.1 & 14 & 29.8 & 1 & & & $0.0481^{2}$ \\
\hline & $50-99 \%$ of pens & 15 & 33.3 & 17 & 36.2 & 2.47 & 0.72 & 8.49 & 0.1511 \\
\hline & All pens & 24 & 53.3 & 16 & 34.0 & 4.38 & 1.32 & 14.50 & 0.0158 \\
\hline \multirow[t]{3}{*}{$\%$ of pens with dirty or very dirty lying areas } & None $^{1}$ & 12 & 26.7 & 25 & 53.2 & 1 & & & $0.0070^{2}$ \\
\hline & $1-49 \%$ & 8 & 17.8 & 11 & 23.4 & 1.52 & 0.48 & 4.75 & 0.4756 \\
\hline & $\geq 50 \%$ & 24 & 53.3 & 11 & 23.4 & 4.73 & 1.76 & 12.72 & 0.0020 \\
\hline
\end{tabular}

Nutrition

Feeding management

Frequency of daily feed delivery felc ${ }^{3}$

Frequency of pushing the feed back to the fence felc ${ }^{3}$

Silage quality

High-grade mildewed silage or a silage with decomposition or loss of structure

Silage with abnormal dry matter content

Grass silage with crude ash content (> 8\%)

Grass silage with $\mathrm{pH}$-value $>4.7$ or corn silage with $\mathrm{pH}$-value $>4.2$

Silage with microbiological deviations

Crude fiber

$\%$ of the herd with milk fat $<3 \%$ in the last $\mathrm{DHI}$ data

Crude fiber per kg DM in the diets $<18 \%$ (PMR) or $<16 \%$ (TMR)

Confounders

Season of the farm visit

$\begin{array}{lllllllll}\geq \text { twice a day }^{1} & 17 & 37.8 & 20 & 42.6 & 1 & & & \\ \text { < twice a day } & 28 & 62.2 & 27 & 57.5 & 1.22 & 0.53 & 2.81 & 0.6407 \\ \geq 5 \text { times a day } & 3 & 6.7 & 8 & 17.0 & 1 & & & 0.1318^{2} \\ \text { 4 times a day } & 12 & 26.7 & 15 & 31.9 & 2.40 & 0.53 & 10.88 & 0.2562 \\ \text { 3 times a day } & 14 & 31.1 & 15 & 31.9 & 2.80 & 0.63 & 12.50 & 0.1773 \\ <3 \text { times a day } & 16 & 35.6 & 8 & 17.0 & 6.00 & 1.26 & 28.50 & 0.0242\end{array}$

No

$\begin{array}{lllll}14 & 31.1 & 23 & 49.0 & 1\end{array}$

$\begin{array}{llllllll}31 & 68.9 & 24 & 51.1 & 2.12 & 0.91 & 4.97 & 0.0834\end{array}$

$\begin{array}{lllll}30 & 66.7 & 33 & 70.1 & 1\end{array}$

$\begin{array}{llllllll}15 & 33.3 & 14 & 29.8 & 1.18 & 0.49 & 2.84 & 0.7145\end{array}$

Yes

$\begin{array}{lllll}3 & 6.4 & 1 & 2.1 & 1\end{array}$

$\begin{array}{llllllll}44 & 93.5 & 46 & 97.9 & 1.47 & 0.23 & 9.21 & 0.6834\end{array}$

$\begin{array}{lllll}43 & 95.6 & 45 & 95.7 & 1\end{array}$

$\begin{array}{llllllll}2 & 4.4 & 2 & 4.3 & 1.05 & 0.14 & 7.76 & 0.9645\end{array}$

Yes

$\begin{array}{lllll}9 & 20.2 & 12 & 25.5 & 1\end{array}$

$\begin{array}{llllllll}36 & 80.0 & 34 & 72.3 & 1.37 & 0.51 & 3.66 & 0.5282\end{array}$

$<3 \%$

$\begin{array}{lllll}30 & 66.7 & 28 & 59.6 & 1\end{array}$

$0.6034^{2}$

$3-5 \%$

$\begin{array}{llllllll}9 & 20.0 & 9 & 19.2 & 0.93 & 0.32 & 2.69 & 0.8983\end{array}$

$>5 \%$

No

$\begin{array}{llllllll}6 & 13.3 & 10 & 21.3 & 0.56 & 0.18 & 1.74 & 0.3170\end{array}$

Yes

$\begin{array}{lllll}18 & 40.0 & 16 & 34.0 & 1\end{array}$

$\begin{array}{llllllll}27 & 60.0 & 31 & 66.0 & 0.77 & 0.33 & 1.81 & 0.5547\end{array}$

Nov-Apr ${ }^{1}$

$\begin{array}{lllll}15 & 33.3 & 26 & 55.3 & 1\end{array}$ 
Table 1 Descriptive and single-factorial analyses of risk factors for health and performance problems in dairy farms in Northern Germany (qualitative variables); a varying number of farms is due to missing values (Continued)

\begin{tabular}{|c|c|c|c|c|c|c|c|c|c|}
\hline \multirow[t]{2}{*}{ Risk factors } & \multirow[t]{2}{*}{ Category } & \multicolumn{2}{|c|}{ Cases } & \multicolumn{2}{|c|}{ Controls } & \multicolumn{4}{|c|}{ Single factorial analyses } \\
\hline & & $\mathrm{N}$ & $\%$ & $\mathrm{~N}$ & $\%$ & $\mathrm{OR}$ & $\mathrm{LCL}$ & $\mathrm{UCL}$ & $P$ \\
\hline & May-Oct & 30 & 66.7 & 21 & 44.7 & 2.48 & 1.06 & 5.77 & 0.0356 \\
\hline \multirow[t]{2}{*}{ Access to pasture } & $\mathrm{No}^{1}$ & 9 & 20.0 & 16 & 34.0 & 1 & & & \\
\hline & Yes & 36 & 80.0 & 31 & 66.0 & 2.06 & 0.80 & 5.32 & 0.1337 \\
\hline
\end{tabular}

Regardless of the health and performance status, only few farms used neither bedding material, mats nor mattresses. However, the more pens with raised cubicles (cubicle without deep bedding with or without mat or mattress) were apparent on a farm the higher was the probability of health and performance problems (Table 1). This finding was only significant in single-factorial analysis. Regarding the dimensions of the cubicles, no statistically significant or relevant differences between the status groups could be revealed.

\section{Hygiene}

Both locations for which the hygienic conditions were evaluated (lying areas and floors) showed statistically significant associations with the herd health status in single-factorial analyses. In multifactorial modeling, the probability of health and performance problems increased by 5.1 -times when more than $50 \%$ of the lying areas were soiled with manure (Table 3 ).

\section{Nutrition}

The more frequently feed was pushed back to the fence for early lactating cows the less probable the farm experienced health and performance problems, yielding in a 6-fold increase of the probability to have health and performance problems when feed was pushed back to the fence less than 3-times per day (single-factorial analysis; Table 1).

Silage quality regarding microbiological and sensory deviations was surprisingly deficient, even in most control farms (Table 1). The low sensory and microbial quality resulted in a lower energy density in the roughage fraction of the diet for fresh lactating cows. In the multifactorial model, a higher energy density in the roughage diets significantly decreased the probability of health and performance problems by 1.3-times per 0.1 net energy content for lactation per kilogram of dry matter (MJ NEL/kg DM) for early lactating cows (Table 3). Also the energy in the complete diet for fresh lactating cows was higher in control farms.

With regard to the crude fiber content in the diet, no significant differences were found between case and control farms.

\section{Discussion}

Study design

A case-control design was considered most appropriate, particularly because several risk factors could be

Table 2 Descriptive and single-factorial analyses of risk factors for health and performance problems in dairy farms in Northern Germany (quantitative variables; no missing values in either status group)

\begin{tabular}{|c|c|c|c|c|c|c|c|c|c|c|c|c|}
\hline \multirow[t]{2}{*}{ Variable } & \multirow[t]{2}{*}{$\mathrm{N}$} & \multicolumn{3}{|l|}{ Cases } & \multirow[t]{2}{*}{ N } & \multicolumn{3}{|c|}{ Controls } & \multicolumn{4}{|c|}{ Single factorial analyses } \\
\hline & & Mean & Median & $\mathrm{CV}$ & & Mean & Median & CV & $\mathrm{OR}$ & $\mathrm{LCL}$ & $\mathrm{UCL}$ & $P$ \\
\hline \multicolumn{13}{|l|}{ Crude fiber } \\
\hline$\%$ of the herd with fat-protein-quotient $<1$ in the $\mathrm{DHI}$ data & 45 & 7.8 & 6.7 & 81.5 & 47 & 8.7 & 7.3 & 70.2 & 0.98 & 0.91 & 1.05 & 0.5228 \\
\hline Ratio of roughage in the complete diets felc ${ }^{1}$ based on DM content & 45 & 58.6 & 58.6 & 15.8 & 47 & 58.2 & 58.0 & 12.4 & 1.01 & 0.97 & 1.05 & 0.5035 \\
\hline \multicolumn{13}{|l|}{ Energy density } \\
\hline Energy density in the roughage diets in $\mathrm{MJ} \mathrm{NEL} / \mathrm{kg} \mathrm{DM}$ felc ${ }^{1}$ & 45 & 6.3 & 6.3 & 3.2 & 47 & 6.4 & 6.4 & 3.5 & 0.06 & 0.01 & 0.51 & 0.0091 \\
\hline Energy density in the complete diets in MJ NEL/kg DM felc ${ }^{1}$ & 45 & 6.9 & 6.9 & 3.3 & 47 & 7.0 & 7.0 & 2.7 & 0.12 & 0.01 & 1.02 & 0.0519 \\
\hline \multicolumn{13}{|l|}{ Quantity of feed } \\
\hline Roughage per cow and day in $\mathrm{kg} D M$ felc ${ }^{1}$ & 45 & 13.4 & 13.2 & 17.4 & 47 & 14.3 & 14.2 & 12.7 & 0.81 & 0.65 & 1 & 0.0541 \\
\hline \multicolumn{13}{|l|}{ Confounder } \\
\hline Herd size (lactating and dry cows) & 45 & 118.9 & 108.0 & 58.9 & 47 & 144.8 & 120.0 & 47.0 & 0.99 & 0.99 & 1.00 & 0.0867 \\
\hline
\end{tabular}

${ }^{1}$ felc for early lactating cows (first 100 days in milk) OR Odds Ratio

LCL Lower Confidence Level

UCL Upper Confidence Level

DHI Dairy Herd Improvement 
Table 3 Results of multifactorial analyses: significant risk factors for health and performance problems in dairy farms in Northern Germany

\begin{tabular}{|c|c|c|c|c|c|}
\hline Risk factors & Category & OR & $\mathrm{LCL}$ & UCL & $P$ \\
\hline \multirow[t]{3}{*}{ Average ratio of cows per watering place } & $\leq 1^{1}$ & 1 & & & $0.0303^{2}$ \\
\hline & $1.01-1.5$ & 0.208 & 0.06 & 0.69 & 0.0122 \\
\hline & $>1.5$ & 0.549 & 0.15 & 1.95 & 0.7308 \\
\hline \multirow[t]{3}{*}{$\%$ of pens with dirty or very dirty lying areas } & None $^{1}$ & 1 & & & $0.0114^{2}$ \\
\hline & $1-49 \%$ & 1.58 & 0.45 & 5.54 & 0.5431 \\
\hline & $\geq 50 \%$ & 5.08 & 1.72 & 15.01 & 0.0062 \\
\hline Energy density in the roughage diets in MJ NEL/kg DM felc ${ }^{3}$ & quantitative & 0.045 & $<0.01$ & 0.46 & 0.0088 \\
\hline
\end{tabular}

${ }^{1}$ Reference category

${ }^{2}$ global $p$-value

${ }^{3}$ felc for early lactating cows (first 100 days in milk)

OR Odds Ratio

LCL Lower Confidence Level

UCL Upper Confidence Level

evaluated simultaneously and in a short period of time $[9,10]$. By design, case-control data are not able to prove causality. However, all factors included in the analyses were selected as their impact on the health of dairy cows was already described elsewhere.

The area under the receiver operating characteristic (ROC) curve in the multifactorial model was 0.774 . Therefore, the model was sufficiently able to correctly predict the response of individual subjects [11]. Hence, a relevant effect of residual confounding was not expected.

\section{Risk factors}

\section{Health management}

Case farms were numerically more often infected by parasites or MAP which might have contributed to the decreased milk yield and the increased mortality [12, 13]. Especially the control of parasites seems to have been neglected on case farms, as more than $50 \%$ of case farms had at least one fecal sample tested positive for intestinal parasites. It is hardly possible to compare these results to other studies because of the study design and the aggregation of data on farm level. However, gastrointestinal parasitism is a widespread problem in other countries, too [14].

The reasons why no differences could be detected concerning the claw health can only be assumed. However, an effect of reverse causation [9] should be taken into account, meaning that some farmers may have already addressed their lameness problems by changing the management, i.e. increasing the frequency of claw trimming to treat lameness. Reverse causation is a well-known phenomenon in casecontrol studies. The cause of the disease may have been long before the time, when the disease sat on and was evaluated. In the current study, possible causes or promoting factors and the herd health status were evaluated at the same time. If any changes concerning the risk factors had been made in the meantime, the true exposure status might have been obscured.

\section{Housing}

Overstocking was found to be a problem despite of the status group. This finding is in accordance with the study by Cook et al. [15] performed in Wisconsin. In contrast, King et al. [16] found on average less cows than cubicles per pen in farms in Canada. However, stocking rates of approximately 1.1 or higher are known to lead to decreased lying and rumination time and increased idle standing $[17,18]$.

In the multifactorial model, a medium stocking density concerning the watering spaces appeared to decrease the probability of chronic herd health problems in case farms compared to control farms. This finding may be due to coincidence or study design as case farms had, by definition, a higher mortality rate and higher culling rate. Therefore, by the time of investigation the stocking rates might have been lower than at the onset of health and performance problems.

The fact, that more case farms had pens with raised cubicles is in accordance with the fact that cows in case farms more often had hock lesions [8]. Hock lesions are known to be found more often in housing systems with raised cubicles [18]. Overcrowding and raised cubicles may have a negative impact on lying time $[19,20]$. Impaired lying time is known to increase the risk of lameness [18, 21, 22] and may cause stress [23]. Thereby, health and performance problems could have been promoted.

Current recommendations concerning the width of the cubicles were not met by either case or control farms. This finding is in accordance with other studies performed in Europe [24, 25]. 


\section{Hygiene}

The fact that case farms had statistically significant more often soiled lying areas is in accordance with the worse hygienic conditions of affected herds compared to control farms [8]. It is common knowledge that insufficient hygiene can increase the incidence of mastitis and lameness [26, 27], which can result in higher culling rates and higher mortality. Hence, it can be suggested that the worse hygienic status may have contributed to the health and performance problems.

\section{Nutrition}

Results of this study emphasize the impact of feeding management (frequency of feed push-ups and feed delivery) even though the differences were not statistically significant in multifactorial modeling. Compared to the study of King et al. [16], the mean of feed push-ups was relatively low on the case as well as on the control farms.

No statistically significant differences could be detected between status groups concerning the quality of silages. However, especially the microbial status of silages and the prevalence of molds and decomposition shows room for improvement.

Concerning the feeding management it can be supposed that the lower energy density in roughage diets may have resulted in a negative energy balance for early lactating cows, which is known to promote various disorders [28, 29]. These might have contributed to the increased mortality, culling rate, rate of downer cows and farmers' impression of a diseased herd. In addition, an energy deficiency and other deficiencies might also have contributed to the decreased milk yield.

Even though no differences could be found concerning the supply of cows with crude fiber, it still might play a crucial role on an individual farm, independent from the status group. Neutral detergent fiber (NDF) and acid detergent fiber (ADF) contents of the diets were not evaluated in this study. These values are currently not available in Germany for many supplements. Future studies should take the content of NDF and ADF into account when assessing differences between crude fiber contents of diets.

\section{Implications for the future}

The results of the study presented here show that there is considerable room for improvement in different aspects of dairy husbandry in Northern Germany. Dairy herds with impaired health and performance differed from control herds with regard to several well-known management factors. Therefore, the following recommendations can be deduced from this study:

- Silage quality, energy density in the ration and feeding management should be checked and revised.
- The stocking rates, and type of bedding should be checked, and if necessary, improvements should be made.

- Infections with parasites should be taken into more thorough account.

- Attention should be focused on the hygiene of the environment of cows, and if necessary, manure management should be improved.

As all these factors relate to different areas of dairy husbandry, we can conclude that a systematic and professional analysis of each farm, e.g. by herd health management services, is necessary to improve performance and health. Future research and discussions should also evaluate, why some farmers were unable to implement some well-known principles of good agricultural practice. Underlying socioeconomic reasons shall be taken into account, e.g. by the use of qualitative methods. Tailored and client-centered support should be provided to farmers. In addition, stable schools, seminars on work organization, professional herd health programs or HACCP-concept based programs might be useful to support farmers [30-32].

\section{Conclusions}

In the current study, associations between well-known risk factors from various areas of farm management and health and performance problems were observed in dairy herds in the northwest of Germany and promising intervention measures were deduced.

Risk factor analyses showed that factors from nearly all areas of farm management were associated with herd health and performance status. However, parasite control, improving silage quality, cow comfort and hygiene appeared to be the most promising measures against health and performance problems. Even though these factors are known for a long time to cause health problems, it cannot be taken as a given that farmers always succeed in fulfilling best agricultural practice. As the risk factors identified relate to different areas of dairy husbandry, we conclude that in case of herd health problems, all areas should be considered systematically, e.g. by herd health management services. Therefore, herd health analyses regarding the farm as a whole are indicated. In particular, individually fitted herd health management programs might be necessary to support farmers in overcoming herd health problems.

\section{Methods}

\section{Study design}

A case-control study was conducted as described by Seyboldt et al. [7] and Jensen et al. [8] Cases were defined to fulfill at least three of the following five criteria: reduced milk yield $(>15 \%$ for at least three months 
compared to the milk yield of the year before), increased mortality ( $>5 \%$ of the herd during the last year), increased culling rate $(>35 \%$ of the herd during the last year or an increase of $>10 \%$ compared to the year before), increased number of downer cows ( $>10 \%$ of the herd during the last year) and farmers' or veterinarians' impression of herd health problems. The controls did not fulfill any of these criteria. All farms were located in the northwest of Germany (Lower Saxony, Schleswig-Holstein, and Northern part of North Rhine-Westphalia). In addition, all participating farms had a loose housing system for lactating cows, minimum herd size of 30 cows and were participating in Dairy Herd Improvement (DHI) milk tests.

Based on the sample size of 46 case and 46 control farms, an odds ratio of $\geq 4$ was detectable (confidence $95 \%$, power $\geq 80 \%$, prevalence of controls $50 \%$; calculated using NCSS Pass ${ }^{\circ}$ ).

All farms were visited once by a team of four research veterinarians who were trained with regard to the examination and data collection processes. During the farm visit, they scored the herd for body condition, hygiene, skin lesions and lameness; interviewed the farmers regarding herd health, management and diet composition; checked the housing conditions; assessed feedstuff; and examined five cows with obvious chronic conditions as well as five cows without obvious conditions. These ten cows were selected in accordance to defined eligibility criteria [7]. If the five cows in a chronically sick condition showed lameness, they were examined in a claw trimming chute. In addition, silage, blood, feces, and bulk milk samples were taken. For all of these procedures, the four observers were trained prior to and during data collection. Standard operating procedures were used (SOPs; see Additional file 1: definition of risk factors). Different sections of data were collected by observers interchangeably. Inter-observer-reliability was not evaluated and observer effect was not considered during risk factor analyses. This was due to the a-priori training, usage of SOP's and permanent training and supervision of the whole observer group by three different senior supervisors. Furthermore, a potential observer effect would not have affected data analyses due to the interchange between data collection parts and the fact that case and control farms were investigated by the same group of study vets, who visited every farm with a different composition of team members.

\section{Confounders}

In addition to the evaluated risk factors, the three following confounders were studied: herd size (quantitative), season during which the farm visit took place (summer: May-October; winter: November-April), and access to a pasture (yes, at least seasonally; no, not at all). Descriptive statistical analyses, as well as single and multifactorial regression analyses, were utilized to assess the association of these confounding variables with casecontrol status.

Although the study region was chosen to reach a homogeneous study population with similar farm structures [33] and the definition of further eligibility criteria, structural differences were found: Slightly more case than control farms were visited during summer (Table 1). Case farms had fewer cows than control farms (Table 2) and cows from case farms more often had access to pastures (Table 1). These findings indicate a more extensive management system in case farms as compared to control farms. This is consistent with DHI data from SchleswigHolstein, where larger farms had a lower culling rate and lower mortality [34]. The confounders did not show a significant impact in the multi-factorial modelling.

\section{Risk factors}

The study veterinarians were asked, what they think which risk factors contribute to the fulfilment of the inclusion criteria on case farms. Based on their answers, four areas with a varying number of risk factors were identified, such as health management (including the sub-areas of infectious diseases and claw health), housing (including the sub-areas of stocking density, dimensions of cubicles, comfort of cubicles, and floors), hygiene, and nutrition (including the sub-areas of feeding management, silage quality, energy density, quantity of roughage, and crude fiber). Risk factors were aggregated at the farm level. An overview of each of the variables investigated is given in the following passages. More detailed definitions of the risk factors and references are provided in the Additional file 1 (definition of risk factors).

\section{Health management}

For the detection of liver flukes, lungworms and intestinal worms, feces samples from the ten cows that were examined clinically were tested for eggs via flotation, separately. In addition, a bulk milk sample was checked for antibodies against liver flukes (IDEXX $\odot)$. For the detection of lungworms, serum samples of the ten examined cows were tested for antibodies. For the detection of MAP, feces samples from the five cows that were in a poor condition and five cows that were in good condition were pooled separately and examined via microbial culture. A farm was considered positive when at least one result from at least one sample was positive. The laboratory analyses were performed by different commercial service providers.

With regard to claw health, the frequency of herd claw trimming (quarterly or more often, every 6 months, 
longer than every 6 months or irregularly) was evaluated in the analyses. In addition, the number out of the ten examined cows with poor claw condition (no cows, one cow, more than one cow) was recorded, and whether high-grade dermatitis digitalis was found on at least one claw of the examined cows that showed lameness was also included in the statistical analyses (yes or no).

\section{Housing}

To evaluate the stocking density, the average ratio of the numbers of cows in the pen per cubicle $(\leq 1=$ no overcrowding; > 1 = overcrowding), feeding spaces and watering places $(<1=$ no overcrowding, $1.01-1.5=$ moderate overcrowding; $>1.5=$ severe overcrowding), were calculated across all pens with lactating or dry cows on the farm (disregarding calving pens or pens for sick cows). In the case of absent feeding fences, one feeding space was defined as $0.75 \mathrm{~m}$ of the feed alley [35]. To calculate the watering space, a cup drinker was assumed to be sufficient for eight cows. In the case of trough watering, a length of $8 \mathrm{~cm}$ was defined as one watering place [35].

To assess the comfort of cubicles, the number of pens with raised cubicles were counted (no pen, at least one pen but not all pens, all pens). It was also noted whether there was a pen without rubber mats or bedding material (no pen, at least one pen).

To evaluate the dimension of the cubicles, the width of cubicles ( $>120 \mathrm{~cm}$; yes or no), average height of neck rails (>115 cm; yes or no), and average distance from neck rail to curb (>195 cm; yes or no) were measured at four randomly chosen cubicles in every pen with lactating or dry cows [35]. Normally, the fourth and the fourth-to-last of the cubicles of the row next to the wall, the fourth-to-last cubicle of the middle row and the fourth cubicle of the row next to the feeding fence were measured. Firstly, the mean of cubicle sizes was calculated at pen level. Secondly, the mean of all pens with lactating or dry cows was calculated to aggregate the data at the farm level and was compared to recommendations mentioned above.

In addition, the percentage of pens with slippery floors was assessed (no pen, 1-50\% of the pens, more than $50 \%$ of the pens) as well as whether or not at least one pen had damaged floors (no pen, at least one pen with damaged floors).

\section{Hygiene}

The percentage of pens with dirty or very dirty floors $(<$ $50 \%$ of the pens, $50-99 \%$ of the pens, $100 \%$ of the pens) and dirty or very dirty lying areas (no pen, at least one pen, but not all pens, all pens) was calculated and included in the analyses.

\section{Nutrition}

To assess feeding management, the frequency of daily feed delivery and frequency of pushing the feed back to the fence for early lactating cows (first 100 days after parturition) were included in the analyses based on farmers' statements (see Additional file 2).

Silage quality was investigated whether or not at least one silage fed to lactating or dry cows was considered to be below current recommendations for sensory status (decomposition, loss of structure or high-grade mildewed; yes or no) assessed by the study veterinarians, crude ash content in grass silages ( $>8 \%$ of dry matter; yes or no), true protein content (grass silage $<50 \%$ true protein of crude protein content; yes or no), dry matter content (grass silage: $<30 \%$ or $>40 \%$ or corn silage: < $28 \%$ or $>35 \%$; yes or no), $\mathrm{pH}$-value (grass silage: $>4.7$ or corn silage: $>4.2$; yes or no), and microbiological deviations (assessment based on recommendations by VDLUFA [36]; at least one silage with profound variation; yes or no). The analyses of the silages concerning the ingredients and the microbiological status were performed by an accredited service provider.

During the interview the farmer was asked for the composition of the diet for fresh lactating cows. Diets were calculated based on farmers' statements using Futter $\mathrm{R}^{\circ}$ (dsp agrosoft). For the silages, the results of the laboratory analyses of the sample taken at the farm visit were used. The declaration of concentrates and supplements was assumed as stated at the product or its delivery receipt [37]. The energy density in the roughage diets (silage, hay, straw) was calculated as composite in the diet for early lactating cows. In addition, the energy density in the whole diet (with concentrates and other feedstuff) for early lactating cows was calculated. Both variables were measured as net energy content for lactation (MJ NEL) per kilogram of dry matter (DM). Additionally, the quantity of fed roughage (kilogram of DM per cow per day; quantitative) for early lactating cows was included in the analysis.

With regard to the potential lack of crude fiber, the ratio of crude fiber within the diet $[<16 \%$ for TMR (total mixed ration), $<18 \%$ for PMR (partial mixed ration; crude fiber was regarded in the fed ration without individual concentrate supply); yes or no] and ratio of roughage to the whole diet (\%; quantitative) were calculated for early lactating cows. Additionally, the percentage of cows in the herd with a fat content $<3 \%$ in milk $(<3 \% ; 3-5 \%$ or $>5 \%$ of the herd) and a fat-proteinquotient $<1$ (\%; quantitative) of the last DHI milk recording before the farm visit were evaluated.

\section{Statistical analysis}

Statistical analyses were performed as described in detail by Jensen et al. [8]. After entry into a relational SQL 
online study database, all analyses were conducted using SAS 9.3 (SAS Institute Inc., Cary, NC, USA). Data were checked for plausibility and missing values. Variables were aggregated at the farm level (statistical unit) as described above and in the Additional file 1 (definition of risk factors). Overall, only nine data points were missing, indicating excellent data quality.

First, a descriptive analysis was performed stratified by case- and control-status. Then, the linearity of the relationship between the quantitative variables and the logit of the case control status was evaluated. Linearity was confirmed graphically using $\mathrm{R}^{\circ}$, version 3.1.1 (R Foundation for Statistical Computing, Vienna, Austria). Two variables (ratio of roughage to the whole ration for early lactating cows and quantity of fed roughage) had a quadratic relationship to the logit of the health status. The quadratic terms of these two variables were included in the statistical analyses. If no quadratic or linear relationship was found, the variables were categorized. Associations among risk factors were investigated using Cramer's V (cut-off: 0.7), Spearman's rank correlation coefficient (cut-off: $|0.8|$ ) or analyses of variance (cut-off for coefficient of determination: 0.64). No association between risk factors was beyond these cut-off values. Therefore, no risk factor was excluded from further analyses. After the tests for association among the risk factors, a single-factorial logistic regression was performed. Variables with $P<0.2$ were included in a multifactorial logistic regression analysis. To achieve an informative model, variables in the multifactorial model were excluded using stepwise backward selection, if the corresponding $P$ value was greater than 0.05 . The correlation matrix of the predictors was investigated to review the associations in the final statistical models. Two-way interactions among the risk factors were included in the backward-selected model and checked for statistical significance with $P<0.1$. After backward selection of the interactions, no interactions with $P<0.1$ remained in the model.

ROC curves were computed for the multifactorial model assessing the performance of the model. Due to the explorative nature of this study, a multiplicity correction was omitted [38].

\section{Supplementary information}

Supplementary information accompanies this paper at https://doi.org/10. 1186/s12917-019-2190-4.

Additional file 1. Definition of risk factors; the table describes the source and the definition of the risk factors

Additional file 2. Questionnaire feeding management; the questionnaire was used to record the feeding management of dry and lactating cows
Additional file 1. Definition of risk factors; the table describes the source and the definition of the risk factors

\section{Abbreviations}

ADF: Acid detergent fiber; C. botulinum: Clostridium botulinum; DHI: Dairy Herd Improvement; felc: For early lactating cows (first 100 days in milk); LCL: Lower Confidence Level; MAP: M. avium ssp. Paratuberculosis; MJ NEL/ kg DM: Net energy content for lactation per kilogram of dry matter; NDF: Neutral detergent fiber; OR: Odds Ratio; PMR: Partial mixed ration; ROC: Receiver operating characteristic; SOP: Standard Operating Procedure; TMR: Total mixed ration; UCL: Upper Confidence Level

\section{Acknowledgements}

We thank the participating farmers and their veterinarians.

\section{Availability of data and material}

Concerning the data availability, we note that our data are available upon request, but only in exceptional cases. The data were collected on an individual basis from farmers. Each participant gave written consent with the understanding that data would not be transferred to any third party. Therefore, any data transfer to interested persons is not allowed without an additional formal contract. Data are available to qualified researchers who sign a contract with the University of Veterinary Medicine Hannover. This contract will include guarantees to the obligation to maintain data confidentiality in accordance with the provisions of the German data protection law. Currently, there exists no data access committee or another body who could be contacted for the data, because there was no need until now.

Interested cooperative partners, who are able to share a contract like described above, may contact: Amely Campe, Department of Biometry, Epidemiology and Information Processing University of Veterinary Medicine, Hannover, Buenteweg 2, 30559 Hannover, Mail: Amely.Campe@tiho-hannover.de.

\section{Authors' contributions}

$\mathrm{MH}$ was the project manager. CS, AC, and MH planned the study. TS, AKW; FG, and PDD visited the farms and collected the data. SW was involved in laboratory analyses of feces samples. KB calculated the diets. FS assigned the silages to quality levels. BS, and $\mathrm{KCJ}$ checked the data for plausibility. KCJ and BS aggregated the data on farm level. KCJ and CF performed the statistical analyses. KCJ wrote the first draft of this paper. All authors read the article, gave advice how to improve it and approved the manuscript.

\section{Funding}

This work was financially supported by the German Federal Ministry of Food, Agriculture and Consumer Protection (BMELV) through the Federal Office for Agriculture and Food (BLE), grant number 2810HS005. The funding body supplied the financial support for human resources, traveling expenses and material costs. The authors were exclusively responsible for the design of the study, collection, analysis, and interpretation of data as well as writing the manuscript. The funding body did not influence any aspect of study.

\section{Ethics approval and consent to participate}

The participation in the study was voluntary. Farmers gave their written consent to participation. All procedures involving animals were carried out in compliance with the Animal Welfare Act (09.12.2010) of Germany and were declared at the State Office for Consumer Protection and Food Safety of Lower Saxony (LAVES: reference No. 13A308), the Ministry for Energy Turnaround, Agriculture, Environment, and Rural Areas of the State Schleswig-Holstein (MELUR: reference No. V 312-7224.123-34) and the State Office for Nature, Environment and Consumer Protection of NorthrhineWestfalia.

\section{Consent for publication}

Not applicable.

\section{Competing interests}

The authors declare that they have no competing interests.

\section{Author details}

${ }^{1}$ Department of Biometry, Epidemiology and Information Processing, WHO

Collaborating Center for Research and Training for Health at the 
Human-Animal-Environment Interface, and Clinic for Cattle, University of Veterinary Medicine Hannover, Foundation, Hannover, Germany. ${ }^{2}$ Clinic for Cattle, University of Veterinary Medicine, Foundation, Hannover, Germany. ${ }^{3}$ Present address: Faculty III, Department Information and Communication, University of Applied Sciences and Arts Hannover, Hannover, Germany. ${ }^{4}$ Present address: Educational and Research Centre for Animal Husbandry, Hofgut Neumuehle, Muenchweiler a.d. Alsenz, Germany. ${ }^{5}$ Present address: Lely Deutschland GmbH, Waldstetten, Germany. ${ }^{6}$ Institute of Food Quality and Food Safety, University of Veterinary Medicine Hannover, Hannover, Germany. ${ }^{7}$ Friedrich-Loeffler-Institut, Institute of Bacterial Infections and Zoonoses, Jena, Germany.

Received: 1 June 2019 Accepted: 25 November 2019 Published online: 05 December 2019

\section{References}

1. Federal Ministry of Food and Agriculture; https://www.bmel.de/SharedDocs/ Downloads/Broschueren/Milchbericht2017.pdf?_blob=publicationFile; .

2. Henrich, P. Based on information of the Federal Office for Agriculture and Food; https://de.statista.com/statistik/daten/studie/153061/umfrage/ durchschnittlicher-milchertrag-je-kuh-in-deutschland-seit-2000/ ; .

3. Böhnel H, Schwagerick B, Gessler F. Visceral botulism-a new form of bovine Clostridium botulinum toxication. J Vet Med A Physiol Pathol Clin Med 2001: http://doi.org/https://doi.org/10.1046/j.1439-0442.2001.00372.x

4. Campe A, Hohmeier S, Koesters S, Hartmann M, Ruddat I, Mahlkow-Nerge K, Heilemann M. Possible causes of unspecific reduced productivity in dairy herds in Schleswig-Holstein: an explorative case-control study. Berl Munch Tierarztl Wochenschr. 2016;129:118-31.

5. Neufeld B, Krüger M, Schwagerick B, Clausen HM, Gerlach A, Wiesmann D et al editors. Chronischer Botulismus; 2010 30-Oct 1st; Göttingen (Germany); Horstmar-Leer (Germany): Agrar- und Veterinärakademie.

6. Fohler S, Discher S, Jordan E, Seyboldt C, Klein G, Neubauer H, Hoedemaker M, Scheu T, Campe A, Jensen KC, Abdulmawjood A. Detection of Clostridium botulinum neurotoxin genes (A-F) in dairy farms from northern Germany using PCR: a case-control study. Anaerobe 2016; https://doi.org/ https://doi.org/10.1016/j.anaerobe.2016.03.008.

7. Seyboldt C, Discher $\mathrm{S}$, Jordan E, Neubauer H, Jensen KC, Campe A, Kreienbrock L, Scheu T, Wichern A, Gundling F, DoDuc P. Occurrence of Clostridium botulinum neurotoxin in chronic disease of dairy cows. Vet Microbiol 2015; http://doi.org/https://doi.org/10.1016/j.vetmic.2015.03.012.

8. Jensen KC, Froemke C, Schneider B, Sartison D, Do Duc P, Gundling F, Scheu T, Wichern A, Fohler S, Seyboldt C, Hoedemaker M. Case-control study on chronic diseases in dairy herds in northern Germany: symptoms at the herd level. Berl Munch Tierarztl Wochenschr. 2017;130:404-14.

9. Dohoo I, Martin W, Stryhn H. Veterinary Epidemiol Res. 2nd ed. Charlottetown: VER Inc; 2009

10. Kreienbrock L, Pigeot I, Ahrens W. Epidemiologische Methoden. 5th ed. Berlin: Springer-Verlag; 2012.

11. Harrell FEJ. Regression Modeling Strategies. 1st ed. New York: Springer; 2001.

12. Hawkins JA. Economic benefits of parasite control in cattle. Vet Parasitol 1993; http://doi.org/https://doi.org/10.1016/0304-4017(93)90056-S.

13. Sanchez J, Dohoo I. A bulk tank milk survey of Ostertagia ostertagi antibodies in dairy herds in Prince Edward Island and their relationship with herd management factors and milk yield. Can Vet J. 2002.

14. Chaparro JJ, Ramírez NF, Villar D, Fernandez JA, Londoño J, Arbeláez C, Olivera M. Survey of gastrointestinal parasites, liver flukes and lungworm in feces from dairy cattle in the high tropics of Antioquia, Colombia Parasite Epidemiol Control 2016; https://doi.org/https://doi.org/10.1016/j.parepi.2016. 05.001.

15. Cook NB, Hess JP, Foy MR, Bennett TB, Brotzman RL. Management characteristics, lameness, and body injuries of dairy cattle housed in highperformance dairy herds in Wisconsin. J Dairy Sci. 2016; http://doi. orghttps://doi.org/10.3168/jds.2016-10956

16. King MTM, Pajor EA, LeBlanc SJ, DeVries TJ. Associations of herd-level housing, management, and lameness prevalence with productivity and cow behavior in herds with automated milking systems. J Dairy Sci. 2016; http:// doi.https://doi.org/10.3168/jds.2016-11329

17. Hill CT, Krawczel PD, Dann HM, Ballard CS, Hovey RC, Falls WA, Grant RJ. Effect of stocking density on the short-term behavioural responses of dairy cows. Appl Anim Behav Sci 2009; https://doi.org/https://doi.org/10.1016/j. applanim.2008.12.012.
18. Van Gastelen S, Westerlaan B, Houwers DJ, Van Eerdenburg FJ. A study on cow comfort and risk for lameness and mastitis in relation to different types of bedding materials. J Dairy Sci 2011; https://doi.org/https://doi.org/10. 3168/jds.2010-4019.

19. Fregonesi JA, Tucker CB, Weary DM. Overstocking reduces lying time in dairy cows. J Dairy Sci 2007; http//doi.org/https:/doi.org/10.3168/jds.2006-794.

20. Krawczel PD, Klaiber LB, Butzler RE, Klaiber LM, Dann HM, Mooney CS, Grant RJ. Short-term increases in stocking density affect the lying and social behavior, but not the productivity, of lactating Holstein dairy cows. J Dairy Sci 2012; https://doi.org/https://doi.org/10.3168/jds.2011-4687.

21. Phillips C, Schofield S. The effect of cubicle and straw yard housing on the behaviour, production and hoof health of dairy cows. Anim Welf. 1994;3:37-44.

22. Leonard FC, O'Connell JM, O'Farrell KJ. Effect of overcrowding on claw health in first-calved Friesian heifers. Br Vet J 1996; http://doi.org/https://doi. org/10.1016/S0007-1935(96)80040-6.

23. Fisher AD, Verkerk GA, Morrow CJ, Matthews LR. The effects of feed restriction and lying deprivation on pituitary-adrenal axis regulation in lactating cows. Livest Prod Sci. 2002; https://doi.org/https://doi.org/10.1016/ S0301-6226(01)00246-9.

24. Veissier I, Capdeville J, Delval E. Cubicle housing systems for cattle: comfort of dairy cows depends on cubicle adjustment. J Anim Sci 2004; http://doi. org/https://doi.org/10.2527/2004.82113321x.

25. Martiskainen $\mathrm{P}$, Koistinen T, Mononen J. Cubicle dimensions affect restingrelated behaviour, injuries and dirtiness of loose-housed dairy cows. In Proceedings of the XIII (13th) International Congress in Animal Hygiene, Tartu, Estonia, 175pp 2007.

26. Philipot JM, Pluvinage P, Cimarosti I, Sulpice P, Bugnard F. Risk factors of dairy cow lameness associated with housing conditions. Vet Res. 1994:25(2-3):244-8.

27. Barkema HW, Schukken YH, Lam TJ, Beiboer ML, Benedictus G, Brand A. Management practices associated with the incidence rate of clinical mastitis. J Dairy Sci 1999; http://doi.org/https://doi.org/10.3168/jds.S00220302(99)75393-2.

28. Collard BL, Boettcher PJ, Dekkers JC, Petitclerc D, Schaeffer LR. Relationships between energy balance and health traits of dairy cattle in early lactation. J Dairy Sci 2000; https:/doi.org/https:/doi.org/10.3168/jds.S0022-0302(00)75162-9.

29. Wathes DC, Cheng Z, Chowdhury W, Fenwick MA, Fitzpatrick R, Morris DG, Patton J, Murphy JJ. Negative energy balance alters global gene expression and immune responses in the uterus of postpartum dairy cows. Physiol Genomics 2009; http:/ doi.org/https://doi.org/10.1152/physiolgenomics.00064.2009.

30. da Silva JC, Noordhuizen JP, Vagneur M, Bexiga R, Gelfert CC, Baumgartner W. Veterinary dairy herd health management in Europe constraints and perspectives. Vet Q. 2006; http://dx.doi.org/https://doi.org/10.1080/ 01652176.2006 .9695203

31. Vaarst M, Nissen TB, Østergaard S, Klaas IC, Bennedsgaard TW, Christensen J. Danish stable schools for experiential common learning in groups of organic dairy farmers. J Dairy Sci 2007; http://doi.org/https://doi.org/10.3168/jds.2006-607.

32. Noordhuizen J, Cannas da Silva J, Boersema SJ, Vieira A. Applying HACCPbased Quality Risk Management on Dairy Farms. 1st ed., Academic Pub Wageningen, Wageningen; 2008.

33. Merle R, Busse M, Rechter G, Meer U. Regionalisation of Germany by data of agricultural structures. Berl Munch Tierarztl Wochenschr. 2012;125(1-2):52-9.

34. Sieck G Zwischenbilanz der MLP im Prüfjahr 2012. 2013. https://www.Ikv-sh. de/home/archiv/115-rib20122zwischenbilanz.

35. Work Group Housing of Cattle. Animal welfare guideline of Lower Saxony for the keeping of dairy cows. Lower Saxony Ministry for Food, Agriculture and Consumer Protection and Lower Saxony State Office for Consumer Protection and Food Safety. 2007. http://www.laves.niedersachsen.de/download/41962/ Tierschutzleitlinie_fuer_die_Milchkuhhaltung.pdf. Accessed 2 July 2016.

36. VDLUFA: Verband Deutscher Landwirtschaftlicher Untersuchungs- und Forschungsanstalten. Mikrobiologische Verfahren. In Band III: Die chemische Untersuchung von Futtermitteln. 3rd ed. Speyer: VDLUFA-Verlag; 1976.

37. Gollub K. Rationsgestaltung und Fütterungsmanagement als Risikofaktoren für das "Chronische Krankheitsgeschehen" in norddeutschen Milchviehbetrieben. 2017. http://elib.tiho-hannover.de/dissertations/gollubk_ ss17.pdf. Accessed 19 July 2017.

38. Bender R, Lange S. Adjusting for multiple testing — when and how?. J Clin Epidemiol 2001; http://doi.org/https://doi.org/10.1016/S0895-4356(00)00314-0.

\section{Publisher's Note}

Springer Nature remains neutral with regard to jurisdictional claims in published maps and institutional affiliations. 